Contributors: JK, BR, and MC were all involved in designing and executing the study as well as in writing the paper. JK collected the data and is guarantor for the paper.

Funding: During data collection, JK's salary was provided by a grant from Hewlett Packard UK.

Conflict of interest: The i-STAT system is manufactured by Hewlett Packard. Hewlett Packard was not involved in any stage of the study design, execution, analysis of data, writing up of the findings, or decisions about publication, although comments on the manuscript were sought as a matter of courtesy to the sponsor.

1 Santrach P, Burritt M. Point of care testing. Mayo Clin Proc 1995;70:493-4

2 Fleisher M. Point of care testing: does it really improve patient care? Clin Biochem 1993;26:6-8.

3 Jatlow P. Point of care laboratory testing in the emergency department. Am J Clin Pathol 1993;100:591.

4 Brown H. Near patient tests are poorly evaluated. BMJ 1997;314:1785.

5 Sands V, Auerbach P, Birnbaum J, Green M. Evaluation of a portable clinical blood analyser in the emergency department. Acad Emerg Med 1995;2:172-8

6 Tsai W, Nash D, Seamonds B, Weir G. Point-of-care versus central laboratory testing: an economic analysis in an academic medical center. Clin Ther 1994;16:898-911.

7 Parvin C, Lo S, Deuser S, Weaver L, Lewis L, Scott M. Impact of point of care testing on patients' length of stay in a large emergency department. Clin Chem 1996;42:711-7.

8 Fleisher M, Schwartz M. Automated approaches to rapid-response testing: a comparative evaluation of point of care and centralised laboratory testing. Am J Clin Pathol 1995;104:S18-25.

9 Saxena S, Wong E. Does the emergency room need a dedicated stat laboratory? Continuous quality improvement as a management tool for the clinical laboratory. Am J Clin Pathol 1993;100:606-10.

10 Frankel H, Rozycki G, Ochsner M, McCabe J, Harviel J, Jeng J, et al. Minimising admission laboratory testing in trauma patients: use of a microanalyser. J Trauma 1994;37:728-36.

11 Kendall JM, Bevan G, Clancy M. A randomised controlled trial of point of care testing in an accident and emergency department: a cost analysis. $J$ Health Services Res Policy (in press).

12 Bingham D, Kendall JM, Clancy M. The portable laboratory, fact or fiction: an evaluation of the accuracy and reproducibility of i-STAT. Ann Clin Biochem (in press).

13 Clancy MJ, Bingham D. Benefits of immediate printing of blood test results within an accident and emergency department. J Accident Emerg Med 1996;13:149-50.
Key messages

- Point of care testing reduced the amount of time doctors spent waiting for results of blood tests when compared to the time spent waiting for results from the hospital laboratory in an accident and emergency department

- The time taken to decide on a management plan was also reduced as a result of the shorter time spent waiting for results of point of care tests

- About $7 \%$ of patients who needed urgent blood testing had changes in treatment in which timing was considered to be critical when point of care testing was used

- Patients did not spend less time in the accident and emergency department even when test results were available more quickly and patient management decisions were made more quickly. This suggests that the availability of test results is not the factor which slows down the arrangement of further care

- Improvements in process, such as a reduction in the time doctors wait for test results and the ability to make clinical decisions more quickly, do not seem to improve clinical outcome in this sample of patients

14 Zaloga G, Hill T, Strickland R, Kennedy D, Visser M, Ford K, et al. Bedside blood gas and electrolyte monitoring in critically ill patients. Crit Care Med 1989;17:920-5.

15 Jacobs E, Vadasi E, Sarkozi L, Colman N. Analytical evaluation of i-STAT portable clinical analyser and use by non-laboratory health care professionals. Clin Chem 1993;39:1069-74.

16 i-STAT Corporation. i-STAT Manual. Princeton, NJ: 1996

17 Woo J, McCabe J, Chauncey D, Schug T, Henry J. The evaluation of a portable clinical analyser in the emergency department. Am J Clin Pathol 1993;100:599-605.

(Accepted 5 December 1997)

\title{
Aspirin for prophylaxis against headache at high altitudes: randomised, double blind, placebo controlled trial
}

\author{
Martin Burtscher, Rudolf Likar, Werner Nachbauer, Michael Philadelphy
}

At altitudes of $3000-5000 \mathrm{~m}$ about $20-50 \%$ of skiers and mountaineers experience headache, the main symptom of acute mountain sickness. ${ }^{1}$ Although most mountaineers know that they should avoid climbing great heights too early on and too fast, they may not always act accordingly. The use of drugs to prevent and treat headaches at high altitudes is therefore widespread, aspirin being one of the most commonly taken. We tested the efficacy of aspirin as prophylaxis against headache at high altitudes.

\section{Subjects, methods, and results}

Twenty nine volunteers with a history of headache at high altitude were randomly assigned in a double blind fashion to receive placebo (eight men, six women, mean age 38 (SD 12) years) or $320 \mathrm{mg}$ aspirin (nine men, six women, mean age 38 (14) years). After examination at low altitude $(600 \mathrm{~m})$, subjects were transported to high altitude $(3480 \mathrm{~m})$ for 24 hours. We gave them three tablets, one every 4 hours, starting 1 hour before arrival at high altitude. We scored headache on a four-point scale $(0=$ none, $1=$ mild,
$2=$ moderate, $3=$ severe) and measured heart rate, blood pressure, and arterial oxygen saturation 1 hour before and 3, 7, 10, and 19 hours after arrival. In addition, subjects exercised for 2 minutes by stepping 60 times up and down a $24 \mathrm{~cm}$ step, at low altitude and within 2-5 hours after arrival at high altitude during which we continuously monitored gas exchange, heart rate, and oxygen saturation.

Seven subjects given placebo and only one given aspirin developed mild to severe headache $(\mathrm{P}=0.01$ for differences in proportions). Although mean oxygen saturation was not different between the two groups 3 hours after arrival at high altitude, the individual values were accurate predictors of the subsequent development of headache. Those who had taken aspirin developed headache at lower oxygen saturation than those who had taken placebo ( $<83 \% v<88 \%$; figure). The difference between mean heart rates at the end of the exercise test at high and low altitudes was smaller in those who had taken aspirin (134 (7) $v 118$ (10) beats/ $\mathrm{min})$ than in those who had taken placebo (142 (13) $v$ 116 (15)) $(\mathrm{P}=0.01$, analysis of variance for repeated measures), in whom ventilation responses to exercise

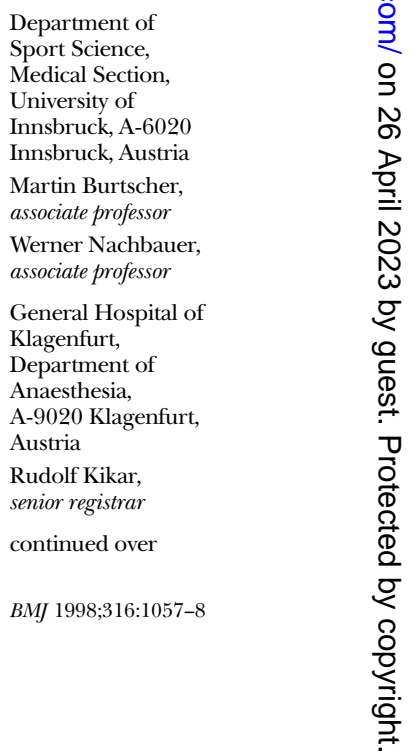


Austrian Alpine Club, Health Section, Innsbruck

Michael Philadelphy, head

Correspondence to: Dr Burtscher Martin.Burtscher@ uibk.ac.at

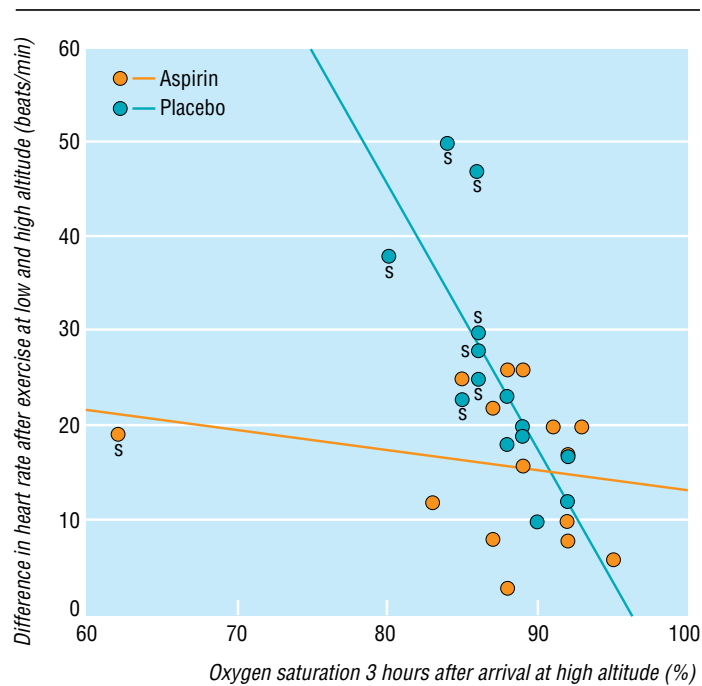

Relation between arterial oxygen saturation values 3 hours after arrival at high altitude, and difference in heart rate after exercise at high and low altitudes in subjects taking placebo or aspirin. s shows subjects who developed headache at high altitude

tended to be higher $(\mathrm{P}=0.07)$. In the placebo group, the difference in heart rate at high altitude was positively correlated with maximum headache scores $(r=0.8, \mathrm{P}<0.01)$ and inversely related to saturation values 3 hours after arrival at high altitude $(r=-0.8$, $\mathrm{P}<0.01$; figure)

\section{Comment}

The incidence of headache at high altitude increases when arterial oxygen saturation and associated oxygen partial pressure decline with increasing altitude. ${ }^{2}$ In this study, however, aspirin prevented headache without improving oxygenation. Pretreatment with aspirin raised the headache threshold, which was indicated by toleration of lower saturation values. Moreover, intake of aspirin was associated with less pronounced cardiorespiratory responses to short term exercise at high altitude. Since acute hypoxia augments prostaglandin concentrations, ${ }^{3}$ and prostaglandins increase ergoreceptor activation and accompanying sympathetic stimulation, ${ }^{4}$ aspirin probably prevents headache by diminishing these responses. Prostaglandins also enhance nociception, and reduced hyperalgesia may therefore have contributed additionally to the prophylactic efficacy of aspirin. Nevertheless, within the first few days of exposure to high altitude, symptoms of acute mountain sickness usually disappear even without drugs. Simultaneously, sympathetic responsiveness decreases due to desensitisation of adrenoceptors, ${ }^{5}$ again indicating some relation between sympathetic activity and development of headaches at high altitude. If this relation is true, aspirin may support adaptation to high altitude by reducing sympathetic activity mediated by prostaglandins.

Contributors: $\mathrm{MB}$ designed the study, examined the subjects, did exercise testing, performed the statistical analysis and took various measurements. RL did the headache scoring and supervised the health of the subjects. WN undertook the randomisation, distribution of tablets, control of data and statistics. MP took various measurements (blood sampling)and did exercise testing.

Funding: This study was supported by the Austrian Society for Mountain Medicine, the Health Section of the Austrian Alpine Club, and Hoffmann-La Roche.

Conflict of interest: None.

1 Maggiorini M, Bühler B, Walter M, Oelz O. Prevalence of acute mountain sickness in the Swiss alps. BMJ 1990;301:853-5.

2 Hackett PH, Rennie D, Levine BD. The incidence, importance, and prophylaxis of acute mountain sickness. Lancet 1976;ii:1149-54.

3 Richalet JP, Hornych A, Rathat C, Aumont J, Larmignat P, Remy P. Plasma prostaglandins, leukotrienes and thromboxane in acute high altitude hypoxia. Respir Physiol 1991;85:205-15.

4 Shepherd JT. Circulatory response to exercise in health. Circulation 1987;76:VI3-10.

5 Richalet JP, Kacimi R, Antezana AM. The cardiac chronotropic function in hypobaric hypoxia. Int J Sports Med 1992;13:(suppl 1):S22-4.

(Accepted 22 October 1997)

\title{
Prevalence of inflammatory bowel disease in British 26 year olds: national longitudinal birth cohort
}

\author{
S M Montgomery, D L Morris, N P Thompson, J Subhani, R E Pounder, A J Wakefield
}

Correspondence to: Dr Montgomery smm@rfhsm.ac.uk continued over
Inflammatory bowel disease has become more common in developed countries this century. Mayberry et al reported incidences of Crohn's disease in Wales of 0.18 cases $/ 10^{5} /$ year in the $1930 \mathrm{~s}$ and 5.95 cases $/ 10^{5} /$ year in the $1970 \mathrm{~s}^{1}$ We investigated the prevalence of inflammatory bowel disease at age 26 years in a nationally representative birth cohort. Associations of sex and social class with risk of the disease have previously been shown, ${ }^{1-3}$ and these were also investigated.

\section{Subjects, methods, and results}

A postal survey of the 1970 British cohort study was conducted in 1995-6 among individuals aged 25 or 26 years, asking if respondents had a diagnosis of Crohn's disease or ulcerative colitis. The cohort study is a longi- tudinal study of those living in England, Scotland, and Wales born 5 to 11 April $1970 .{ }^{4}$ The target population was estimated as 16000 , and we sent questionnaires to the 13099 cohort members whom we traced. In all, 9803 completed questionnaires were returned; 309 addresses were identified as no longer current; and 12 people refused to participate. Excluding invalid and untraced addresses, the response rate was $77 \%$. The social statistics research unit at City University, London, provided most (7430) of the addresses. To minimise bias, we traced the remaining 2373 cohort members through a letter forwarding service provided by the Driver and Vehicle Licensing Agency. The cohort remained largely representative, with some loss from the most disadvantaged groups: the proportion in social class $\mathrm{V}$ at birth dropped from $6.4 \%$ to $4.7 \%$ in the respondents. 